\title{
Interventions for reducing extinction risk in chytridiomycosis-threatened amphibians
}

Running title: Reducing extinction risk in amphibians

B. C. Scheele ${ }^{\text {a, b, }}$ †, D. A. Hunter ${ }^{\text {b }}$, L. F. Grogan ${ }^{c}$, L. Berger ${ }^{c}$, J. E. Kolby ${ }^{c,}$, M. S. McFadden e, G. Marantelli ${ }^{\text {f }}$ L. F. Skerratt ${ }^{\mathrm{c}}$, D. A. Driscoll ${ }^{\mathrm{a}}$

${ }^{a}$ ARC Centre of Excellence for Environmental Decisions, National Environmental Research Program Environmental Decisions Hub, Fenner School of Environment and Society, Forestry Building [48], Australian National University, Canberra, ACT 0200, Australia

${ }^{\mathrm{b}}$ NSW Office of Environment and Heritage, Queanbeyan, NSW 2620, Australia

${ }^{c}$ One Health Research Group, School of Public Health, Tropical Medicine and Rehabilitation Sciences, James Cook University, Townsville, Queensland 4811, Australia.

d IUCN SSC Amphibian Specialist Group, Regional Co-Chair (Honduras).

e Taronga Conservation Society Australia, Mosman, NSW 2088, Australia.

${ }^{\mathrm{f}}$ Amphibian Research Centre, PO Box 959, Merlynston, Victoria 3058, Australia.

† Address for correspondence: Australian National University, email: ben.scheele@anu.edu.au

Key words: amphibian decline, Batrachochytrium dendrobatidis, chytrid, disease management, emerging infectious disease, frog, wildlife management

\begin{abstract}
Wildlife diseases pose an increasing threat to biodiversity and are a major management challenge. A striking example of this threat is the emergence of chytridiomycosis. Despite diagnosis of chytridiomycosis as an important driver of global amphibian declines 15 years ago, researchers have yet to devise effective large scale management responses other than biosecurity measures to mitigate disease spread and the establishment of disease-free captive assurance colonies prior to or during disease outbreaks. We examined the development of management actions that can be implemented after an epidemic in surviving populations. We developed a conceptual framework with clear interventions to guide experimental management and applied research so that further extinctions of amphibian species threatened by chytridiomycosis might be prevented. Within our framework, there are 2 management approaches: reducing Batrachochytrium dendrobatidis (the fungus that causes chytridiomycosis) in the environment or on amphibians and increasing the capacity of populations to persist despite increased mortality from disease. The latter approach emphasizes that mitigation does not necessarily
\end{abstract}


need to focus on reducing disease-associated mortality. We propose promising management actions that can be implemented and tested based on current knowledge and that include habitat manipulation, antifungal treatments, animal translocation, bioaugmentation, head starting, and selection for resistance. Case studies where these strategies are being implemented will demonstrate their potential to save critically endangered species. 


\section{Introduction}

In a globalizing world, emerging infectious diseases are a growing threat to biodiversity (Daszak 2000; Fisher et al. 2012) and can have a rapid and widespread impact on wildlife, driving species to extinction (Berger et al. 1998; Joseph et al. 2013). Despite the rise of disease as a key conservation challenge, the management of wildlife diseases affecting biodiversity, especially non-mammals, remains in its infancy (Joseph et al. 2013).

Chytridiomycosis, caused by the pathogenic skin fungus Batrachochytrium dendrobatidis (Bd), has devastated amphibian communities globally and is considered the worst recorded wildlife disease (Berger et al. 1998; Skerratt et al. 2007). Infection with Bd has been detected in 516 of 1240 (42\%) amphibian species sampled (Olson et al. 2013), and a conservative estimate suggests that chytridiomycosis has caused the severe decline or extinction of over 200 species (Skerratt et al. 2007). Amphibians are a functionally important group, and their loss is likely to have major ramifications throughout ecosystems (Whiles et al. 2013).

Although experimental management strategies are underway (Woodhams et al. 2011), there are few studies on the in situ management of species threatened by chytridiomycosis (Joseph et al. 2013; Zippel et al. 2011). To date, amphibian disease management has generally targeted mitigating disease spread and securing captive assurance colonies rather than restoring populations after an epidemic. Existing literature is largely directed toward policy makers, regional managers, and researchers rather than on-the-ground wildlife managers (see Department of the Environment and Heritage 2006; Mendelson et al. 2006; Woodhams et al. 2011). We devised a framework to guide management that includes experimental strategies that directly target reduction of chytridiomycosis in host populations and outline strategies to improve population buffering capacity against disease-induced mortality, which is only briefly covered in previous disease management recommendations (Department of the Environment and Heritage 2006; Woodhams et al. 2011). We summarize new and updated strategies aimed at mitigating the impact of chytridiomycosis to assist wildlife managers to select interventions.

Although populations of some species that declined have recovered (Newell et al. 2013), other species remain at low abundance or continue to decline and face increased risk of extinction (Hunter et al. 2010; Vredenburg et al. 2010). One of the main reasons for this elevated extinction risk is on-going mortality and restricted recruitment caused by endemic chytridiomycosis (Murray et al. 2009; Muths et al. 2011; Phillott et al. 2013). In addition, many remnant populations have limited connectivity, occur in suboptimal habitat, and are likely to have increased vulnerability to stochastic events and other threatening processes (Murray et al. 2009; Puschendorf et al. 2011). 
A huge research effort over the last decade has resulted in Bd becoming one of the most studied wildlife pathogens. The ecology and pathogenesis of chytridiomycosis is relatively well understood, Bd distribution has been mapped and modeled, high-risk species have been identified, biosecurity protocols have been implemented, captive assurance colonies have been established, and antifungal treatments and disinfectants (including chemical, physical, and biological treatments) have been developed for implementation in controlled environments (e.g., Murray et al. 2011; Woodhams et al. 2011). However, a major gap remains in translating research into post-epidemic, in situ management actions. It is crucial that we overcome a fear of in-field interventions and use existing knowledge to test novel solutions such as those suggested in Table 1 (Berger \& Skerratt 2012).

Here we propose a new framework to provide greater clarity for setting conservation objectives and to highlight approaches to practical management of species threatened by chytridiomycosis. In the framework, management strategies are grouped into 2 broad approaches and within each approach, we classified management strategies into 3 action classes based on whether strategies are implemented in situ, involve amphibian introductions, or are ex situ. We then provide a scientific underpinning for novel management strategies that hold considerable promise, including habitat manipulation, in situ antifungal treatment, animal translocations, bioaugmentation, head starting, and ex situ selection for resistance. We considered examples where researchers are implementing these strategies in conjunction with conservation agencies. Given the limited application of interventions to date, we hope that showcasing techniques currently being tested will inform and stimulate the development and implementation of conservation strategies for Bd threatened species. 
Table 1. A framework for action to maintain populations of amphibians threatened by Batrachochytrium dendrobatidis (Bd) when the short-term goal is to secure these populations in captivity and in the wild.

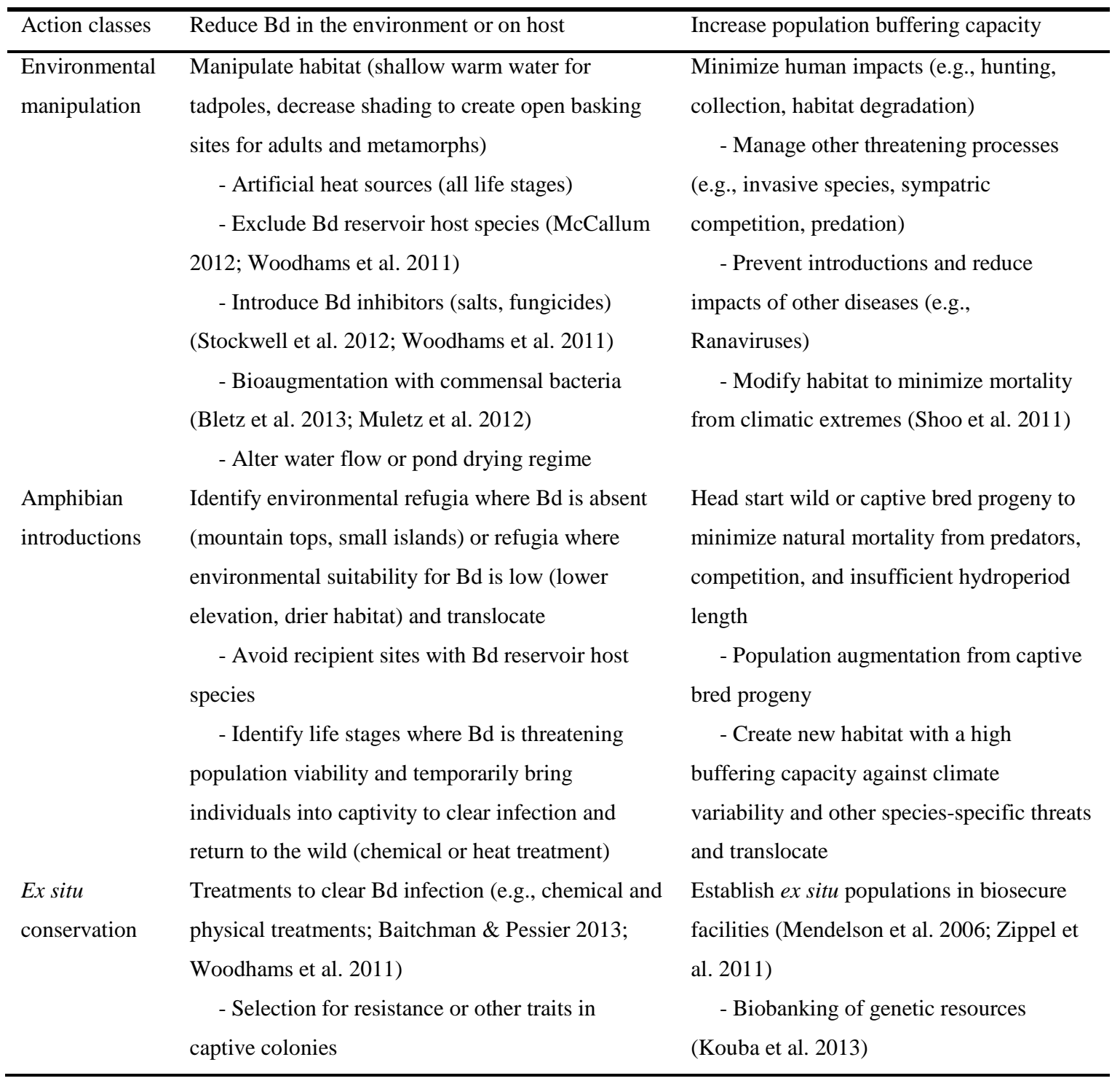

\section{Time frames defining the scope of management objectives}

A key challenge to managing species affected by chytridiomycosis is the difficulty of developing long-term solutions. Thus, we divided this challenge into 2 separate goals based on time frames: the short-term goal of establishing robust holding populations of Bd-threatened species in response to immediate threats in the wild (Table 1) and the long-term goal of establishing self-sustaining wild populations. Because these goals operate on different time frames, they often require different approaches and techniques. Intensive and expensive options are acceptable as short-term emergency measures, whereas long-term sustainable measures need 
to be more cost effective and take into account that species may remain reliant on conservation management, to various degrees, into the future.

We focused on developing actions that can be implemented immediately to achieve the first goal of securing populations that have experienced major declines. Predicting and mitigating disease spread and determining "trigger points” for intervening when chytridiomycosis does spread have been addressed elsewhere (Berger \& Skerratt 2012; Department of Primary Industries 2010; Murray et al. 2011). It is important that robust holding populations of chytridiomycosis-threatened species are secured both in captivity and in the wild to facilitate the establishment of self-sustaining wild populations. Although long-term solutions remain elusive, achieving short-term goals will provide a platform for research into long-term goals such as natural or assisted evolution of resistance and behavioral modification (e.g., Richards-Zawacki 2010; Savage \& Zamudio 2011; Venesky et al. 2012).

\section{Managing Bd-threatened species}

Our conceptual framework (Table 1) provides a summary of different management options to help managers identify appropriate conservation actions. We identified 2 management approaches: reducing $\mathrm{Bd}$ in the environment or on the host and increasing population buffering capacity against Bd-induced mortality, emphasizing that intervention need not focus directly on reducing disease. Within these 2 approaches, there are 3 action classes: environmental manipulation, amphibian introductions, and ex situ conservation (Table 1). Thus far, the management of Bd-threatened species has focused on establishment of ex situ captive colonies (Mendelson et al. 2006; Zippel et al. 2011). This is a critical first stage and the only option for some species. However, where possible we propose that this should be combined with techniques to maintain species in situ to reduce costs, avoid negative consequences associated with captive breeding (e.g., reduced fitness; Araki et al. 2007), and facilitate the natural evolution of host resistance. This is where environmental manipulation and introductions can contribute.

\section{Environmental manipulation}

\section{Manipulation to reduce Bd}

In remnant populations of Bd-threatened species, environmental manipulation can be implemented to decrease infection rates and burdens and hence improve host survival. Environmental manipulation is an in situ method that has been successfully used to combat wildlife diseases and can be implemented across a wide range of scales (Wobeser 2007). For example, decreased shading and improved drainage of nesting sites minimized avian cholera, and creating artificial watering points lowered harmful trematode infections in moose (Alces 
alces; Wobeser 2002). Environmental and biological factors can exert a strong influence on infectious diseases; therefore, manipulating environmental conditions can influence disease development (Wobeser 2007). The thermal preference of Bd is relatively well understood; optimal growth is from 17 to $25^{\circ} \mathrm{C}$ (Piotrowski et al. 2004; Stevenson et al. 2013). On either side of this range $\left(5-17^{\circ} \mathrm{C}\right.$ and $25-28{ }^{\circ} \mathrm{C}$ ) growth is slow. Above $30^{\circ} \mathrm{C}$ Bd dies (Piotrowski et al. 2004), and mortality is rapid at higher temperatures ( $4 \mathrm{~h}$ at $37^{\circ} \mathrm{C}$; Johnson et al. 2003). The fungus is not tolerant of desiccation and is killed within $1 \mathrm{~h}$ of drying (Johnson et al. 2003). Field studies and models are consistent with these results and suggest that factors affecting $\mathrm{Bd}$ growth (particularly temperatures above $25^{\circ} \mathrm{C}$ during the month prior to sampling) are key limiting factors for chytridiomycosis dynamics (Murray et al. 2013; Richards-Zawacki 2010; Rowley \& Alford 2013). Furthermore, high climatic variability, especially unusually low temperatures, increases the impact of chytridiomycosis (Rohr et al. 2013).

Warm water $\left(>30^{\circ} \mathrm{C}\right.$ ) provides an important refuge from Bd for aquatic amphibians (Forrest \& Schlaepfer 2011; Savage et al. 2011). Because overhanging vegetation lowers the water temperature of amphibian breeding ponds (Freidenburg \& Skelly 2004), the strategic removal of patches of vegetation, particularly over shallow, nearshore locations is likely to create warm water refuges for infected individuals (Geiger et al. 2011). Field evidence suggests that decreased shading of ponds is linked to lower Bd infection intensities (Heard et al. 2013; Raffel et al. 2010). Water temperature may also be increased through the creation of nearshore, shallow water areas that warm up rapidly or by changing substrate color or texture. For example, Bufo americanus tadpoles can aggregate in shallow pockets of warm water adjacent to scrap sheet metal in breeding ponds (Beiswenger 1977).

Environmental manipulation may also be used to increase temperature in terrestrial habitats. Many riverine species bask to raise body temperature, and increasing the amount of solar radiation reaching basking sites through vegetation removal could clear or reduce infection (Fig. 1). Puschendorf et al. (2011) hypothesized that for the highly susceptible species Litoria lorica short term exposure to warm rock temperatures along a sunny stream section may be facilitating population persistence with endemic Bd. This is supported by a follow-up study showing that exposing $\mathrm{Bd}$ cultures to $33^{\circ} \mathrm{C}$ for just $1 \mathrm{~h}$ significantly reduced fungal growth (Daskin et al. 2011).

In situations where habitat modification is not possible, artificial heat sources on land or in water could provide refuges for infected individuals to reduce or clear infection. This strategy has been suggested for protecting bat populations in North America threatened by white nose syndrome (Boyles \& Willis 2010). Artificial heat sources provide opportunities for individuals 
to maintain preferred body temperatures, which are often higher than ambient air temperatures, and are likely to be particularly effective for species that display behavioral fever (Murphy et al. 2011; Richards-Zawacki 2010).

Developing chemical treatments for environmental application is an area of important research; salt and several agricultural products clear or reduce Bd infections under laboratory conditions (Hanlon et al. 2012; McMahon et al. 2013; Stockwell et al. 2012). For example, thiophanatemethyl, a widely used, broad-spectrum fungicide, cleared infection in tadpoles when applied $6 \mathrm{~d}$ after experimental inoculation, but tadpoles grew larger than controls, suggesting side effects may occur (Hanlon et al. 2012). Similarly, the addition of salt to pond environments is a promising strategy for inhibiting Bd growth; however, it may also have negative effects (Heard et al. 2013; Stockwell et al. 2012; Woodhams et al. 2011). Recently, Geiger and Schmidt (2013) used General Tonic (acriflavin/methylene blue) to reduce Bd in captivity, and further research is underway to evaluate the effectiveness of pond applications. Therefore, although use of chemicals in natural habitats holds promise, it is important to determine concentrations and rates of application and assess potential negative side effects.

Bioaugmentation could help maintain threatened populations and facilitate successful reintroductions (Joseph et al. 2013; Woodhams et al. 2011). Bioaugmentation involves inoculating amphibian hosts or habitats with microbes that produce metabolites that inhibit $\mathrm{Bd}$ growth and survival (reviewed in Bletz et al. 2013). Locally occurring microbes are most appropriate and Bletz et al. (2013) provide methods to identify microbes that both inhibit Bd and persist on target hosts. Because soil provides an important reservoir for beneficial microbes (Loudon et al. 2014) that can be transmitted to amphibians (Muletz et al. 2012), environmental application appears feasible. As with other interventions, research to improve understanding is needed while field applications are concurrently assessed.

Figure 1. Examples of environmental manipulation.

(a) The critically endangered Litoria spenceri is restricted to a single stream (stream 1) in Kosciuszko National Park, Australia, and is threatened by endemic chytridiomycosis. (b) Recipient stream (stream 2) in the park identified through broad-scale surveys where captive bred $L$. spenceri will be introduced. (c) Temperature profiles for representative $L$. spenceri basking sites from streams 1 and 2. Overhanging vegetation was pruned from half the locations on stream 1 at the end of January. 

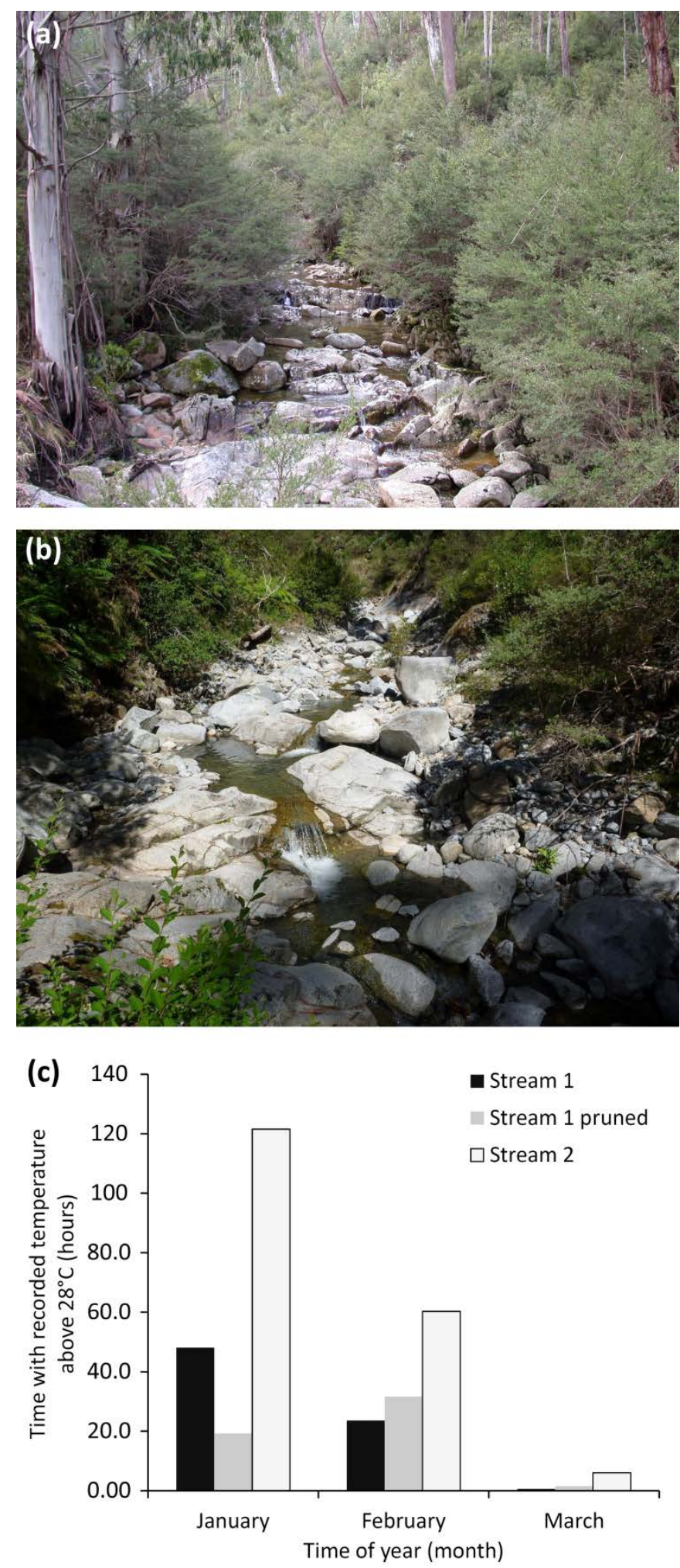

\section{Manipulation to increase population buffering capacity}

An alternative approach to directly reducing Bd pressure in disease-threatened amphibian populations is to minimize other sources of mortality. Amphibian populations can tolerate adult mortality from Bd when recruitment is sufficiently high (Muths et al. 2011; Phillott et al. 2013; Tobler et al. 2012). Habitat loss and degradation are key threatening processes for many 
amphibian species (Stuart et al. 2004), and it is crucial to protect habitat for species threatened by chytridiomycosis. Introduced species can also increase juvenile and adult mortality, and their exclusion can increase population size (e.g., Vredenburg 2004). However, increased population densities following the removal of introduced species will theoretically increase Bd transmission, and this risk should be considered against potential benefits (Briggs et al. 2010). Finally, in many amphibian populations climatic extremes are a major source of mortality (Shoo et al. 2011). To minimize drought-induced recruitment failure, amphibian breeding habitats can be manipulated to increase hydroperiod, and adult mortality can be reduced through the creation of moist refuges (see Shoo et al. 2011). When manipulating habitat, it is important to consider the relative effects of different sources of mortality because there may be trade-offs between improved survivorship and improved habitat for Bd (Murray et al. 2011).

\section{Amphibian introductions}

\section{Introductions to environments unfavorable for Bd}

When Bd cannot be controlled in situ, translocations can be used to move animals to environments unfavorable to Bd growth or to Bd-free locations. Animal translocation can mitigate infectious disease in mammals (Wobeser 2002), but remains untested for combating chytridiomycosis. We propose the translocation of animals into environmental refugia within or near their former range. Refugia must have suitable characteristics (Hoegh-Guldberg et al. 2008) and either occur within the physiological stress limits of the target species or be manipulated to remain within those limits. Refugia can be identified through a combination of Bd field sampling and distribution modeling (Puschendorf et al. 2009; Puschendorf et al. 2013). In general, refugia are most likely to occur at lower elevations where environmental temperatures exceed the optimum for Bd growth, or in drier areas. However, other factors, such as the absence of disease reservoir species, may be equally important in some circumstances (Joseph et al. 2013). The effectiveness of amphibian introductions to new areas is being evaluated in Kosciuszko National Park, Australia, where the critically endangered Litoria spenceri is restricted to a single stream (Fig. 1a) and is threatened by endemic chytridiomycosis. A captive breeding colony has been established and will provide offspring for reintroduction at the source site following canopy reduction as well as experimental introduction to a second stream (Fig. 1b) that has naturally low canopy cover, a warm microclimate (Fig. 1c), and no reservoir hosts or introduced predatory fish.

Although translocations have considerable promise, they can have unintended consequences, and potential benefits and risks require careful evaluation (see Hoegh-Guldberg et al. 2008; McLachlan et al. 2007). Importantly, it is crucial to follow biosecurity protocols to mitigate the 
risk of disease spread and subsequent outbreaks (Department of the Environment and Heritage 2006; Zippel et al. 2011).

\section{Introductions to increase population buffering capacity}

It may be possible to counteract the population impacts of increased mortality caused by Bd by adding captive bred individuals to wild populations. Two strategies that build on traditional reintroduction approaches are head starting and population augmentation (Fig. 2). Head starting involves raising wild harvested individuals, typically eggs or tadpoles, to an optimal age for release and thus enabling survival through periods of naturally high mortality (e.g., due to predation) or high Bd-induced mortality or Bd exposure. To devise effective head starting strategies for each species, it is crucial to know which life history stage has highest exposure to Bd or undergoes mortality from chytridiomycosis. For example, in upland rainforest streams in Central America chytridiomycosis causes much higher mortality in metamorphizing individuals than in adults (Kolby et al. 2010). The Honduras Amphibian Rescue and Conservation Center (HARCC) is working to address this concern and replenish the population of adult reproductive frogs. To enhance survival, late development stage tadpoles will be brought into captivity, treated for and cleared of infection, and maintained at the biosecure HARCC facility through metamorphosis (Figs. 2a and 2b). These frogs will be raised in captivity past their most Bdvulnerable life phase and then released as young adults at their capture site. Head starting has an important benefit over ex situ breeding programs: individuals for reintroduction can be produced quickly, which removes the challenges and failures associated with captive breeding in species with diverse reproductive and husbandry requirements. Therefore, in systems where Bd is endemic but adults continue to produce offspring, head starting eggs or tadpoles could contribute to population survival within their natural habitat.

When recipient sites are unavailable and habitat manipulation is not possible, creating new habitat for translocated animals is likely to be useful. Human-created ponds already provide important refuges for chytridiomycosis-threatened amphibians (Heard et al. 2013). Benefits of habitat creation include a high level of control of environmental conditions and avoidance of impacts on natural habitat for non-target species. A variety of habitats should be created (Lesbarreres et al. 2010) that include warm environments where individuals can reduce or clear Bd infection. Created habitat should be designed to minimize the impacts of other threats such as fish predation or drought-induced recruitment failure (Shoo et al. 2011) because increased recruitment may compensate for chytridiomycosis-induced mortality (cf. Muths et al. 2011). 
Figure 2. Examples of head starting programs.

(a) Plectrohyla dasypus, a critically endangered species that will be collected, treated for Batrachochytrium dendrobatidis infection, and released as part of the Honduras Amphibian Rescue and Conservation Center (HARCC) program. (b) An amphibian room at Lancetilla Botanical Gardens, Honduras, where Batrachochytrium dendrobatidis-free amphibians in the HARCC program will be head started and raised for future reintroductions into Cusuco National Park, Honduras. (c) Artificial ponds in natural breeding habitat in Kosciuszko National Park, Australia, where captive and wild bred eggs from the critically endangered Pseudophryne corroboree have been placed to prevent contact with co-occurring reservoir hosts and eliminate mortality from premature pond drying. (d) A recently metamorphosed P. corroboree emerging from one of the artificial ponds in (c).
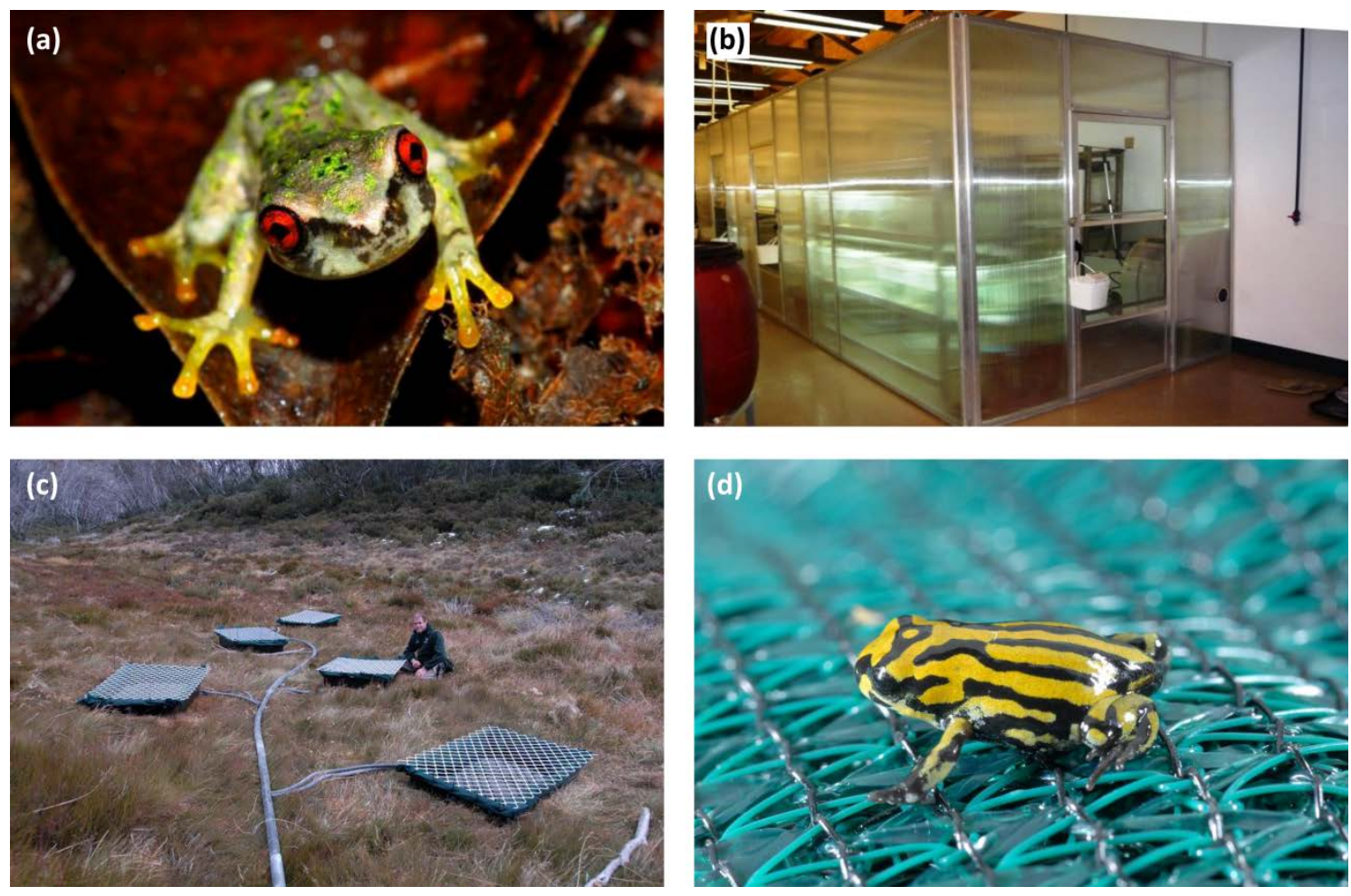

\section{Ex situ conservation}

\section{$\underline{\text { Selection for resistance }}$}

For species relying on captive colonies to survive, maintaining the genetic diversity of founding individuals through generations in captivity is important because this diversity cannot be regained. However, selecting for increased disease resistance could facilitate population persistence with Bd infection and thus lead to sustainable populations (see Venesky et al. 2012; Venesky et al. 2013 for discussion on selection for increased disease resistance and tolerance). 
A population of Mixophyes fleayi recovered naturally due to increased adult longevity, which suggests that in this species disease resistance was evolving (Newell et al. 2013). Direct selection for disease resistance in captivity involves exposing frogs to $\mathrm{Bd}$ and breeding from survivors or from those that survive for longer- these can be treated with antifungals to avoid mortality (Venesky et al. 2012). Alternatively genetic markers for disease resistance (Savage \& Zamudio 2011) might be used to identify resistant individuals for breeding. In addition, breeding stock should be updated with potentially resistant individuals currently surviving in the wild under natural selection. Similarly, selection for increased reproductive capacity may enable some populations to persist by offsetting chytridiomycosis-induced adult mortality (Muths et al. 2011; Phillott et al. 2013). Selection pressure should be moderate to avoid inbreeding depression for other traits by occasional outbreeding with less resistant or reproductive individuals (Frankham et al. 2011). Finally, in all ex situ operations it is important to develop treatments to clear Bd infection for use in emergency situations in the case of a breach in biosecurity and an outbreak of chytridiomycosis in the captive colony.

\section{Chemical and heat treatment}

Antifungal compounds and heat treatment can be used to reduce or clear Bd infection (Woodhams et al. 2011). Itraconazole is the most commonly used chemical treatment and can clear infection in a range of species (Baitchman \& Pessier 2013). Voriconazole (Martel et al. 2011), chloramphenicol (Young et al. 2012), and terbinafine hydrochloride (Bowerman et al. 2010) can also clear infection in various species, providing alternatives to itraconazole. Speciesspecific optimization is needed for chemical treatments because itraconazole use has been associated with toxicity in tadpoles and adults (Baitchman \& Pessier 2013) and may lead to increased infection rates after subsequent Bd exposure (Cashins et al. 2013). Heat treatment offers an inexpensive alternative to chemical treatments (Chatfield \& Richards-Zawacki 2011). Exposure to temperatures from 27 to $37^{\circ} \mathrm{C}$ has cleared infection in a variety of species (Baitchman \& Pessier 2013; Geiger et al. 2011; Woodhams et al. 2011), although it was ineffective in other species (Woodhams et al. 2012). Chemical and heat treatments should be trialled on a small number of individuals to confirm effectiveness and safety for each species. Baitchman \& Pessier 2013) provide a detailed review, including dosage rates and exposure times, for chemical and heat treatments. In populations with predictable seasonal die-offs, we suggest collecting and holding amphibians for short course treatment during times of peak burdens to improve survival. Although reducing burdens may increase survival during die-offs, failure to clear infection enables the development of drug resistance by pathogens. 


\section{Choosing a strategy}

Assessing which management strategies are most suitable for a given species depends on a detailed understanding of Bd dynamics and species ecology. Interventions against Bd should target amphibian life history stages most affected by disease or at high risk of Bd exposure. Ecological surveys are needed to identify outbreaks, ongoing declines, and prioritize high-risk populations (Murray et al. 2011; Skerratt et al. 2008). We provide an example illustrating how a multifaceted response can be developed to target specific life history stages from the 2 management approaches and 3 action classes (Table 1, Fig. 3). For most species, a variety of approaches implemented at different spatial scales will be necessary, such as head starting at sites where the environment has been manipulated to decrease Bd suitability (Fig. 3). Given the lack of proven effective strategies, all interventions should be implemented within an experimental framework. To optimize progress, research aimed at understanding the mechanisms underlying interventions should occur concurrently with their application. 


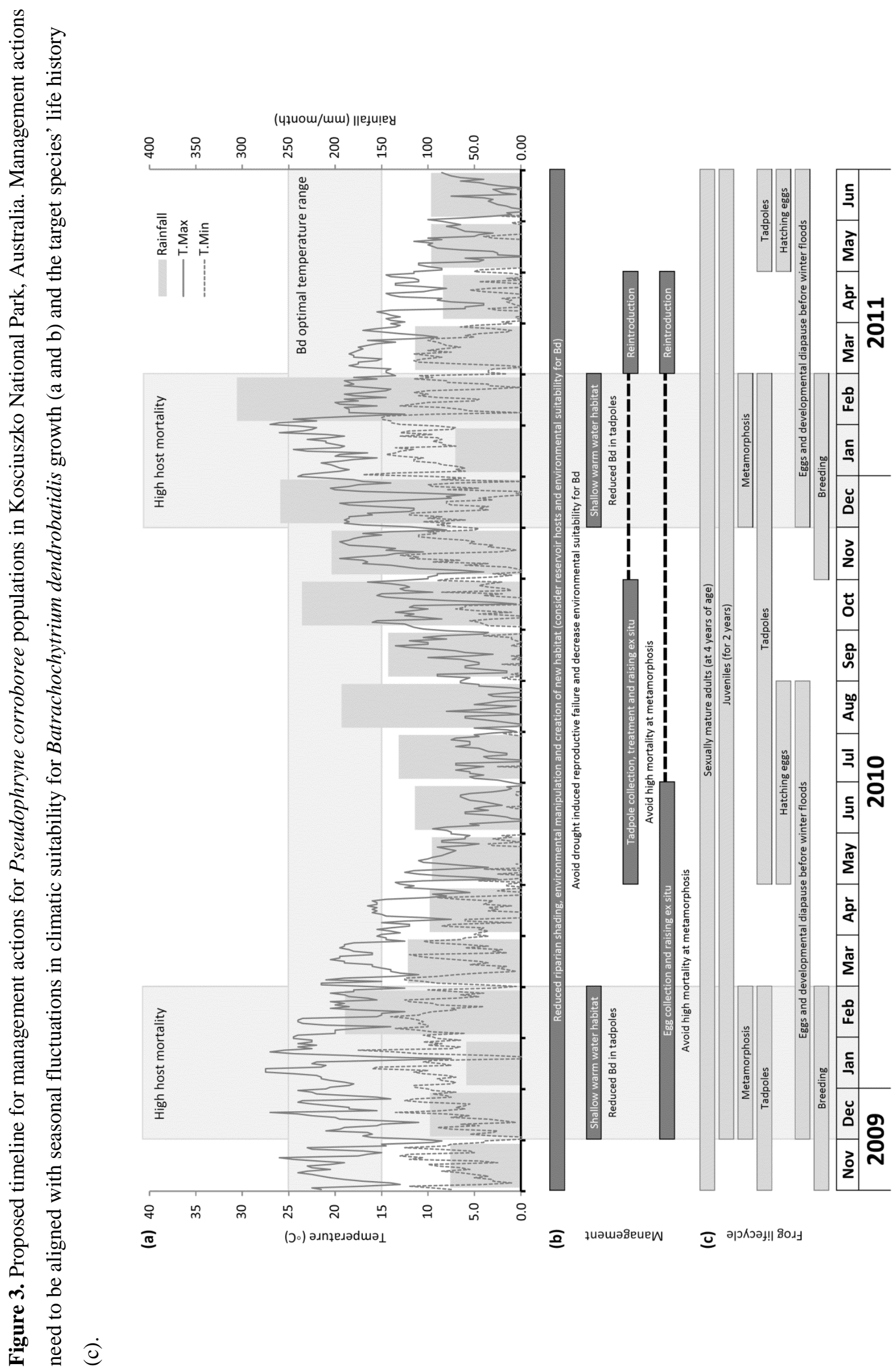




\section{Conclusion}

Preserving habitat is not enough to mitigate the effects of novel diseases, which require direct intervention to protect species. More amphibian extinctions are expected in the next decade (Bletz et al. 2013); thus, the consequences of not acting are likely to be more severe than conducting experimental management, such as translocations into natural or created refugia. We suggest testing relatively simple, locally adapted strategies rather than waiting for the invention of a broadly applicable solution to chytridiomycosis. Developing strategies to secure chytridiomycosis threatened species is an achievable challenge and will enable the longer-term goal of species recovery. Managers and conservation biologists in government, universities, zoos, and conservation groups must collaborate closely to identify and undertake research focused on achieving this objective (Mendelson et al. 2006). Coordination of ex situ responses under the Amphibian Ark umbrella provides a promising example of collaboration (Zippel et al. 2011). We hope managers and researchers investigate the ideas presented here and develop other complementary strategies. It is imperative that we act now using existing knowledge to establish in situ and ex situ populations of Bd-threatened amphibian species. Failure to do so will only increase the number of amphibian extinctions caused by chytridiomycosis.

\section{Acknowledgments}

We thank R. Speare for helpful discussions on chytridiomycosis management. Comments from 2 anonymous referees greatly improved the article. L.B. and L.G. were supported by Australian Research Council grants FT100100375 and LP110200240. 


\section{REFERENCES}

Araki, H., B. Cooper, and M. S. Blouin. 2007. Genetic effects of captive breeding cause a rapid, cumulative fitness decline in the wild. Science 318:100-103.

Baitchman, E. J., and A. P. Pessier. 2013. Pathogenesis, diagnosis, and treatment of amphibian chytridiomycosis. Veterinary Clinics of North America Exotic Animal Practice 16:669685.

Beiswenger, R. E. 1977. Diel patterns of aggregative behavior in tadpoles of Bufo americanus, in relation to light and temperature. Ecology 58:98-108.

Berger, L., and L. Skerratt. 2012. Disease Strategy Chytridiomycosis (Infection with Batrachochytrium dendrobatidis) Version 1, 2012. Department of Sustainability, Environment, Water, Populations and Communities, Public Affairs, Commonwealth of Australia, Canberra. Available at http://www.environment.gov.au/system/files/resources/387d3e66-3cdc-4676-8fed759328277da4/files/chytrid-fungus-manual.pdf $>$.

Berger, L., R. Speare, P. Daszak, D. E. Green, A. A. Cunningham, C. L. Goggin, R. Slocombe, M. A. Ragan, A. D. Hyatt, K. R. McDonald, H. B. Hines, K. R. Lips, G. Marantelli, and H. Parkes. 1998. Chytridiomycosis causes amphibian mortality associated with population declines in the rain forests of Australia and Central America. Proc Natl Acad Sci U S A 95:9031-9036.

Bletz, M. C., A. H. Loudon, M. H. Becker, S. C. Bell, D. C. Woodhams, K. P. C. Minbiole, and R. N. Harris. 2013. Mitigating amphibian chytridiomycosis with bioaugmentation: characteristics of effective probiotics and strategies for their selection and use. Ecology Letters 16:807-820.

Bowerman, J., C. Rombough, S. R. Weinstock, and G. E. Padgett-Flohr. 2010. Terbinafine hydrochloride in ethanol effectively clears Batrachochytrium dendrobatidis in amphibians. Journal of Herpetological Medicine and Surgery 20:24-28.

Boyles, J. G., and C. K. R. Willis. 2010. Could localized warm areas inside cold caves reduce mortality of hibernating bats affected by white-nose syndrome? Frontiers in Ecology and the Environment 8:92-98.

Briggs, C. J., R. A. Knapp, and V. T. Vredenburg. 2010. Enzootic and epizootic dynamics of the chytrid fungal pathogen of amphibians. Proceedings of the National Academy of Sciences of the United States of America 107:9695-9700.

Cashins, S. D., L. F. Grogan, M. McFadden, D. Hunter, P. S. Harlow, L. Berger, and L. F. Skerratt. 2013. Prior infection does not improve survival against the amphibian disease chytridiomycosis. Plos One 8:7. 
Chatfield, M. W. H., and C. L. Richards-Zawacki. 2011. Elevated temperature as a treatment for Batrachochytrium dendrobatidis infection in captive frogs. Diseases of Aquatic Organisms 94:235-238.

Daskin, J. H., R. A. Alford, and R. Puschendorf. 2011. Short-term exposure to warm microhabitats could explain amphibian persistence with Batrachochytrium dendrobatidis. Plos One 6: e26215.

Daszak, P. 2000. Emerging infectious diseases of wildlife - threats to biodiversity and human health. Science 287:443.

Department of Primary Industries, P., Water and Environment,. 2010. Tasmanian Chytrid Management Plan. Department of Primary Industries, Parks, Water and Environment, Tasmania, Australia. Available from http://www.dpiw.tas.gov.au/inter,nsf/Attachments/LJEM8887K5/\$FILE/Tasmanian\%20Frog\%20Management\%20Plan.pdf (accessed January 2014).

Department of the Environment and Heritage 2006. Threat Abatement Plan: infection of amphibians with chytrid fungus resulting in chytridiomycosis. Australian Government, Canberra, ACT.

Fisher, M. C., D. A. Henk, C. J. Briggs, J. S. Brownstein, L. C. Madoff, S. L. McCraw, and S. J. Gurr. 2012. Emerging fungal threats to animal, plant and ecosystem health. Nature 484:186-194.

Forrest, M. J., and M. A. Schlaepfer. 2011. Nothing a hot bath won't cure: infection rates of amphibian chytrid fungus correlate negatively with water temperature under natural field settings. PLoS One 6:e28444.

Frankham, R., J. D. Ballou, M. D. B. Eldridge, R. C. Lacy, K. Ralls, M. R. Dudash, and C. B. Fenster. 2011. Predicting the Probability of Outbreeding Depression. Conservation Biology 25:465-475.

Freidenburg, L. K., and D. K. Skelly. 2004. Microgeographical variation in thermal preference by an amphibian. Ecology Letters 7:369-373.

Geiger, C. C., E. Kupfer, S. Schar, S. Wolf, and B. R. Schmidt. 2011. Elevated temperature clears chytrid fungus infections from tadpoles of the midwife toad, Alytes obstetricans. Amphibia-Reptilia 32:276-280.

Geiger, C. C., and B. R. Schmidt. 2013. Laboratory tests of antifungal agents to treat tadpoles against the pathogen Batrachochytrium dendrobatidis. Diseases of Aquatic Organisms 103:191-197.

Hanlon, S. M., J. L. Kerby, and M. J. Parris. 2012. Unlikely remedy: fungicide clears infection from pathogenic fungus in larval southern leopard frogs (Lithobates sphenocephalus). Plos One 7:8. 
Heard, G. W., M. P. Scroggie, N. Clemann, and D. S. L. Ramsey. 2013. Wetland characteristics influence disease risk for a threatened amphibian. Ecological Applications 24:650-662.

Hoegh-Guldberg, O., L. Hughes, S. McIntyre, D. B. Lindenmayer, C. Parmesan, H. P. Possingham, and C. D. Thomas. 2008. Assisted colonization and rapid climate change. Science 321:345-346.

Hunter, D. A., R. Speare, G. Marantelli, D. Mendez, R. Pietsch, and W. Osborne. 2010. Presence of the amphibian chytrid fungus Batrachochytrium dendrobatidis in threatened corroboree frog populations in the Australian Alps. Diseases of Aquatic Organisms 92:209-216.

Johnson, M. L., L. Berger, L. Philips, and R. Speare. 2003. Fungicidal effects of chemical disinfectants, UV light, desiccation and heat on the amphibian chytrid Batrachochytrium dendrobatidis. Diseases of Aquatic Organisms 57:255-260.

Joseph, M. B., J. R. Mihaljevic, A. L. Arellano, J. G. Kueneman, D. L. Preston, P. C. Cross, and P. T. J. Johnson. 2013. Taming wildlife disease: bridging the gap between science and management. Journal of Applied Ecology 50:702-712.

Kolby, J. E., G. E. Padgett-Flohr, and R. Field. 2010. Amphibian chytrid fungus Batrachochytrium dendrobatidis in Cusuco National Park, Honduras. Diseases of Aquatic Organisms 92:245-251.

Kouba, A. J., R. E. Lloyd, M. L. Houck, A. J. Silla, N. Calatayud, V. L. Trudeau, J. Clulow, F. Molinia, C. Langhorne, C. Vance, L. Arregui, J. Germano, D. Lermen, and G. Della Togna. 2013. Emerging trends for biobanking amphibian genetic resources: The hope, reality and challenges for the next decade. Biological Conservation 164:10-21.

Lesbarreres, D., M. S. Fowler, A. Pagano, and T. Lode. 2010. Recovery of anuran community diversity following habitat replacement. Journal of Applied Ecology 47:148-156.

Loudon, A. H., D. C. Woodhams, L. W. Parfrey, H. Archer, R. Knight, V. McKenzie, and R. N. Harris. 2014. Microbial community dynamics and effect of environmental microbial reservoirs on red-backed salamanders (Plethodon cinereus). Isme Journal 8:830-840.

Martel, A., P. Van Rooij, G. Vercauteren, K. Baert, L. Van Waeyenberghe, P. Debacker, T. W. J. Garner, T. Woeltjes, R. Ducatelle, F. Haesebrouck, and F. Pasmans. 2011. Developing a safe antifungal treatment protocol to eliminate Batrachochytrium dendrobatidis from amphibians. Medical Mycology 49:143-149.

McCallum, H. 2012. Disease and the dynamics of extinction. Philosophical Transactions of the Royal Society B-Biological Sciences 367:2828-2839.

McLachlan, J. S., J. J. Hellmann, and M. W. Schwartz. 2007. A framework for debate of assisted migration in an era of climate change. Conservation Biology 21:297-302. 
McMahon, T. A., J. M. Romansic, and J. R. Rohr. 2013. Nonmonotonic and monotonic effects of pesticides on the pathogenic fungus Batrachochytrium dendrobatidis in culture and on tadpoles. Environmental Science \& Technology 47:7958-7964.

Mendelson, J. R., III, K. R. Lips, R. W. Gagliardo, G. B. Rabb, J. P. Collins, J. E. Diffendorfer, P. Daszak, R. Ibanez D, K. C. Zippel, D. P. Lawson, K. M. Wright, S. N. Stuart, C. Gascon, H. R. da Silva, P. A. Burrowes, R. L. Joglar, E. La Marca, S. Loetters, L. H. du Preez, C. Weldon, A. Hyatt, J. V. Rodriguez-Mahecha, S. Hunt, H. Robertson, B. Lock, C. J. Raxworthy, D. R. Frost, R. C. Lacy, R. A. Alford, J. A. Campbell, G. Parra-Olea, F. Bolanos, J. J. Calvo Domingo, T. Halliday, J. B. Murphy, M. H. Wake, L. A. Coloma, S. L. Kuzmin, M. S. Price, K. M. Howell, M. Lau, R. Pethiyagoda, M. Boone, M. J. Lannoo, A. R. Blaustein, A. Dobson, R. A. Griffiths, M. L. Crump, D. B. Wake, and E. D. Brodie, Jr. 2006. Biodiversity - Confronting amphibian declines and extinctions. Science 313:48-48.

Muletz, C. R., J. M. Myers, R. J. Domangue, J. B. Herrick, and R. N. Harris. 2012. Soil bioaugmentation with amphibian cutaneous bacteria protects amphibian hosts from infection by Batrachochytrium dendrobatidis. Biological Conservation 152:119-126.

Murphy, P. J., S. St-Hilaire, and P. S. Corn. 2011. Temperature, hydric environment, and prior pathogen exposure alter the experimental severity of chytridiomycosis in boreal toads. Diseases of Aquatic Organisms 95:31-42.

Murray, K. A., D. Rosauer, H. McCallum, and L. F. Skerratt. 2011. Integrating species traits with extrinsic threats: closing the gap between predicting and preventing species declines. Proceedings of the Royal Society B-Biological Sciences 278:1515-1523.

Murray, K. A., L. F. Skerratt, S. Garland, D. Kriticos, and H. McCallum. 2013. Whether the weather drives patterns of endemic amphibian chytridiomycosis: a pathogen proliferation approach. Plos One 8:11.

Murray, K. A., L. F. Skerratt, R. Speare, and H. McCallum. 2009. Impact and dynamics of disease in species threatened by the amphibian chytrid fungus, Batrachochytrium dendrobatidis. Conservation Biology 23:1242-1252.

Muths, E., R. D. Scherer, and D. S. Pilliod. 2011. Compensatory effects of recruitment and survival when amphibian populations are perturbed by disease. Journal of Applied Ecology 48:873-879.

Newell, D. A., R. L. Goldingay, and L. O. Brooks. 2013. Population recovery following decline in an endangered stream-breeding frog (Mixophyes fleayi) from subtropical Australia. Plos One 8:8.

Olson, D. H., D. M. Aanensen, K. L. Ronnenberg, C. I. Powell, S. F. Walker, J. Bielby, T. W. J. Garner, G. Weaver, M. C. Fisher, and G. Bd Mapping. 2013. Mapping the global 
emergence of Batrachochytrium dendrobatidis, the amphibian chytrid fungus. Plos One 8:13.

Phillott, A. D., L. F. Grogan, S. D. Cashins, K. R. McDonald, L. Berger, and L. F. Skerratt. 2013. Chytridiomycosis and seasonal mortality of tropical stream-associated frogs 15 years after introduction of Batrachochytrium dendrobatidis. Conservation Biology 27:1058-1068.

Piotrowski, J. S., S. L. Annis, and J. E. Longcore. 2004. Physiology of Batrachochytrium dendrobatidis, a chytrid pathogen of amphibians. Mycologia 96:9-15.

Puschendorf, R., A. C. Carnaval, J. VanDerWal, H. Zumbado-Ulate, G. Chaves, F. Bolanos, and R. A. Alford. 2009. Distribution models for the amphibian chytrid Batrachochytrium dendrobatidis in Costa Rica: proposing climatic refuges as a conservation tool. Diversity and Distributions 15:401-408.

Puschendorf, R., L. Hodgson, R. A. Alford, L. F. Skerratt, and J. VanDerWal. 2013. Underestimated ranges and overlooked refuges from amphibian chytridiomycosis. Diversity and Distributions 19:1313-1321.

Puschendorf, R., C. J. Hoskin, S. D. Cashins, K. McDonald, L. F. Skerratt, J. Vanderwal, and R. A. Alford. 2011. Environmental Refuge from Disease-Driven Amphibian Extinction. Conservation Biology 25:956-964.

Raffel, T. R., P. J. Michel, E. W. Sites, and J. R. Rohr. 2010. What drives chytrid infections in newt populations? Associations with substrate, temperature, and shade. Ecohealth 7:526-536.

Richards-Zawacki, C. L. 2010. Thermoregulatory behaviour affects prevalence of chytrid fungal infection in a wild population of Panamanian golden frogs. Proceedings of the Royal Society B-Biological Sciences 277:519-528.

Rohr, J. R., T. R. Raffel, A. R. Blaustein, P. T. Johnson, S. H. Paull, and S. Young. 2013. Using physiology to understand climate-driven changes in disease and their implications for conservation. Conservation Physiology 1:cot022.

Rowley, J. J. L., and R. A. Alford. 2013. Hot bodies protect amphibians against chytrid infection in nature. Scientific Reports 3:4.

Savage, A. E., M. J. Sredl, and K. R. Zamudio. 2011. Disease dynamics vary spatially and temporally in a North American amphibian. Biological Conservation 144:1910-1915.

Savage, A. E., and K. R. Zamudio. 2011. MHC genotypes associate with resistance to a frogkilling fungus. Proceedings of the National Academy of Sciences of the United States of America 108:16705-16710.

Shoo, L. P., D. H. Olson, S. K. McMenamin, K. A. Murray, M. Van Sluys, M. A. Donnelly, D. Stratford, J. Terhivuo, A. Merino-Viteri, S. M. Herbert, P. J. Bishop, P. S. Corn, L. Dovey, R. A. Griffiths, K. Lowe, M. Mahony, H. McCallum, J. D. Shuker, C. Simpkins, 
L. F. Skerratt, S. E. Williams, and J. M. Hero. 2011. Engineering a future for amphibians under climate change. Journal of Applied Ecology 48:487-492.

Skerratt, L. F., L. Berger, H. B. Hines, K. R. McDonald, D. Mendez, and R. Speare. 2008. Survey protocol for detecting chytridiomycosis in all Australian frog populations. Diseases of Aquatic Organisms 80:85-94.

Skerratt, L. F., L. Berger, R. Speare, S. Cashins, K. R. McDonald, A. D. Phillott, H. B. Hines, and N. Kenyon. 2007. Spread of chytridiomycosis has caused the rapid global decline and extinction of frogs. Ecohealth 4:125-134.

Stevenson, L. A., R. A. Alford, S. C. Bell, E. A. Roznik, L. Berger, and D. A. Pike. 2013. Variation in thermal performance of a widespread pathogen, the amphibian chytrid fungus Batrachochytrium dendrobatidis. Plos One 8:14.

Stockwell, M. P., J. Clulow, and M. J. Mahony. 2012. Sodium chloride inhibits the growth and infective capacity of the amphibian chytrid fungus and increases host survival rates. Plos One 7:7.

Stuart, S. N., J. S. Chanson, N. A. Cox, B. E. Young, A. S. L. Rodrigues, D. L. Fischman, and R. W. Waller. 2004. Status and trends of amphibian declines and extinctions worldwide. Science 306:1783-1786.

Tobler, U., A. Borgula, and B. R. Schmidt. 2012. Populations of a susceptible amphibian species can grow despite the presence of a pathogenic chytrid fungus. Plos One 7:8.

Venesky, M. D., J. R. Mendelson, B. F. Sears, P. Stiling, and J. R. Rohr. 2012. Selecting for tolerance against pathogens and herbivores to enhance success of reintroduction and translocation. Conservation Biology 26:586-592.

Venesky, M. D., T. R. Raffel, T. A. McMahon, and J. R. Rohr. 2013. Confronting inconsistencies in the amphibian-chytridiomycosis system: implications for disease management. Biological Reviews 89:477-483.

Vredenburg, V. T. 2004. Reversing introduced species effects: Experimental removal of introduced fish leads to rapid recovery of a declining frog. Proceedings of the National Academy of Sciences of the United States of America 101:7646-7650.

Vredenburg, V. T., R. A. Knapp, T. S. Tunstall, and C. J. Briggs. 2010. Dynamics of an emerging disease drive large-scale amphibian population extinctions. Proceedings of the National Academy of Sciences of the United States of America 107:9689-9694.

Whiles, M. R., R. O. Hall, Jr., W. K. Dodds, P. Verburg, A. D. Huryn, C. M. Pringle, K. R. Lips, S. S. Kilham, C. Colon-Gaud, A. T. Rugenski, S. Peterson, and S. Connelly. 2013. Disease-driven amphibian declines alter ecosystem processes in a tropical stream. Ecosystems 16:146-157.

Wobeser, G. 2002. Disease management strategies for wildlife. Revue Scientifique Et Technique De L Office International Des Epizooties 21:159-178. 
Wobeser, G. A. 2007. Disease in Wild Animals: Investigation and Management. Springer, New York.

Woodhams, D. C., J. Bosch, C. J. Briggs, S. Cashins, L. R. Davis, A. Lauer, E. Muths, R. Puschendorf, B. R. Schmidt, B. Sheafor, and J. Voyles. 2011. Mitigating amphibian disease: strategies to maintain wild populations and control chytridiomycosis. Frontiers in Zoology 8:23.

Woodhams, D. C., C. C. Geiger, L. K. Reinert, L. A. Rollins-Smith, B. Lam, R. N. Harris, C. J. Briggs, V. T. Vredenburg, and J. Voyles. 2012. Treatment of amphibians infected with chytrid fungus: learning from failed trials with itraconazole, antimicrobial peptides, bacteria, and heat therapy. Diseases of Aquatic Organisms 98:11-25.

Young, S., R. Speare, L. Berger, and L. F. Skerratt. 2012. Chloramphenicol with fluid and electrolyte therapy cures terminally ill green tree frogs (Litoria caerulea) with chytridiomycosis. Journal of Zoo and Wildlife Medicine 43:330-337.

Zippel, K., K. Johnson, R. Gagliardo, R. Gibson, M. McFadden, R. Browne, C. Martinez, and E. Townsend. 2011. The amphibian ark: a global community for ex situ conservation of amphibians. Herpetological Conservation and Biology 6:340-352. 